\title{
EPÊNTESE VOCÁLICA NO PORTUGUÊS DO SUL DO BRASIL: VARIÁVEIS EXTRALINGÜÍSTICAS
}

\author{
Gisela Collischonn*
}

\section{Introdução}

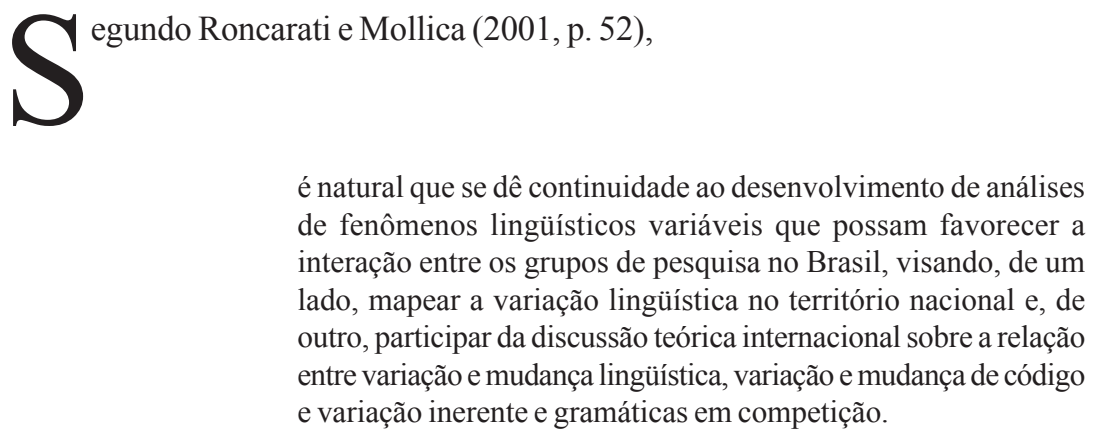

* Universidade Federal do Rio Grande do Sul. 
COLLISCHONN, G. Epêntese vocálica no português do Sul...

A pesquisa que relatamos neste trabalho quer contribuir exatamente para isso. Defendendo a pluralidade teórico-metodológica que caracteriza a pesquisa sociolingüística realizada no Brasil, Roncarati e Mollica dizem ainda, "o estudo em tempo real e em tempo aparente tem de resgatar a importância da atuação dos componentes social, estrutural, lexical e individual, responsáveis conjuntamente pela mudança"; com isso, "impõe-se a constituição e a utilização de inúmeros corpora, quer em falantes de L1 e L2 em aquisição, quer em gramáticas já consolidadas do português em estágios atuais e mais antigos do idioma".

Nesse sentido, os diversos corpora que constituem o Banco Varsul têm um valor inegável, especialmente (mas não exclusivamente!) no que se refere às comunidades bilíngües. Diversas pesquisas em variação fonológica que são relatadas em Bisol e Brescancini (2002) apontam para mudanças em curso nas comunidades bilíngües. Essas mudanças são no sentido das características de fala dos centros regionais. Há uma espécie de nivelamento em curso, operando de maneira bastante rápida. Assim, fica nítido o valor que as entrevistas realizadas nessas comunidades no início dos anos 90 têm, já que retratam não só identidades regionais, mas também fixam como fotografias um momento da nossa realidade sociolingüística que já começa a ficar para trás. Há mais de um tipo de bilíngües, nas amostras de cada uma dessas cidades. Entre os mais jovens a situação de bilingüismo tende a ser diferente da dos mais velhos. Não obstante, a situação de bilingüismo em maior ou menor grau ainda caracteriza os falantes dessas comunidades.

A pesquisa que discutimos no presente trabalho trata da incidência de vogal epentética para desfazer encontros consonantais em palavras como admitir, tecnologia, opção, entre outras. A partir de 1998, dedicamo-nos a investigar esse fenômeno, nos moldes da pesquisa sociolingüística quantitativa, utilizando os dados do Projeto Varsul. Naquele momento, partíamos de uma análise do fenômeno da epêntese de acordo com a teoria derivacional da sílaba de Itô (1986), baseada também em Pigott (1995). Segundo essa análise, a epêntese ocorreria ainda no componente lexical da fonologia do português brasileiro, como resultado do processo de silabação. Durante a silabação, uma consoante não apta a ocupar uma posição silábica de ataque ou coda permaneceria não ligada a nenhum nó silábico (chamamos essa consoante de consoante perdida). A existência de uma dessas consoantes perdidas na representação fonológica desencadearia a criação de uma sílaba estrutural, desprovida ainda de núcleo vocálico, mas a qual permite a associação da consoante perdida em posição de ataque. Mais tarde, no pós-léxico, essa sílaba seria preenchida com uma vogal e a mora correspondente. A pesquisa procurava testar as predições do modelo 
teórico adotado, mas acabou revelando outros aspectos do fenômeno; neste trabalho, discutimos algumas dessas características.

Nas primeiras etapas, restringimo-nos aos falantes com escolaridade até o segundo grau (antigo colegial) das três capitais do sul do Brasil, e das cidades interioranas, que fazem parte do corpus do Projeto Varsul, Blumenau (SC) e Panambi (RS), nas quais ocorre contato com dialetos do alemão, e Flores da Cunha (RS), na qual ocorre contato com dialetos italianos.

A pesquisa apontou, em primeiro lugar, a relevância de variáveis referentes ao contexto fonológico (tipo de consoante envolvida, papel do acento), os quais foram discutidos no trabalho publicado em Bisol e Brescancini (2002). Aqui, focalizamos questões de variação entre falantes.

O fenômeno tem uma distribuição bastante característica no espaço geográfico: além de existirem diferenças entre os três grupos de falantes da amostra das capitais, os falantes das capitais, tomados em conjunto, apresentaram taxas de realização de epêntese consideravelmente mais altas do que o conjunto dos falantes das cidades interioranas. Essas constatações podem ser comprovadas na tabela abaixo.

TABELA 1 - TAXA DE REALIZAÇÃO DE EPÊNTESE CONFORME A DISTRIBUIÇÃO GEOGRÁFICA (ESCOLARIDADE ATÉ SEGUNDO GRAU)

\begin{tabular}{l|l|l|l}
\hline & Aplicação/Total & $\%$ & Peso relativo \\
\hline Porto Alegre & $107 / 183$ & 58 & 0,78 \\
Curitiba & $103 / 199$ & 52 & 0,65 \\
Florianópolis & $64 / 149$ & 43 & 0,53 \\
Flores da Cunha & $78 / 170$ & 46 & 0,55 \\
Panambi & $44 / 181$ & 24 & 0,27 \\
Blumenau & $43 / 186$ & 23 & 0,26 \\
Total & $439 / 1068$ & 41 & \\
\hline
\end{tabular}

Input: 0,38

Significância: 0,010

As amostras de Panambi e Blumenau apresentavam, ambas, taxas bem mais baixas, ao passo que os falantes de Flores da Cunha apresentavam uma taxa de realização intermediária. Essa distribuição no espaço geográfico, sugere tratar-se de uma variável do tipo indicador, que traz informação sobre a origem geográfica, e não de um estereótipo ou de um marcador social.

Uma vez que, a partir de 2000, o Banco Varsul já dispunha da coleta de dados referente ao nível superior (de Porto Alegre, pelo menos), buscou-se um detalhamento da variável escolaridade (o que poderia indicar um comportamento como marcador). Na seção seguinte, detalharemos as análises feitas para as quatro faixas de escolaridade para as capitais e, nas subseqüentes, trataremos das amostras das cidades de Panambi, Blumenau e Flores da Cunha, respectivamente. 


\section{As amostras das capitais - o papel da escolaridade}

As amostras das capitais evidenciam o papel da escolaridade no fenômeno em estudo. Resultados mais robustos são obtidos para a amostra de Porto Alegre.

Numa análise estatística que engloba as quatro faixas escolares (primário, ginásio, colegial e superior), os resultados se mostram nítidos, conforme se verifica na tabela 2.

TABELA 2 - TAXA DE EPÊNTESE NA AMOSTRA DE PORTO ALEGRE (QUATRO FAIXAS ESCOLARES)

\begin{tabular}{l|ll|l}
\hline & Aplicação/Total & $\%$ & Peso relativo \\
\hline Primário & $30 / 40$ & 75 & 0,80 \\
Ginásio & $25 / 34$ & 74 & 0,80 \\
Colegial & $47 / 108$ & 44 & 0,52 \\
Superior & $56 / 173$ & 32 & 0,35 \\
Total & $158 / 355$ & 45 & \\
\hline
\end{tabular}

Input: 0,45

Significância: 0,037

Os informantes menos escolarizados (primário e ginásio) apresentam alta taxa de realização do fenômeno $(0,80)$, ao passo que os mais escolarizados realizam menos epêntese $(0,35$ e 0,52$)$.

É importante observar que o número de formas-alvo vai aumentando consideravelmente com o aumento da escolaridade.

Em Curitiba, embora os resultados não mostrem tão nitidamente quanto em Porto Alegre a diferença entre as faixas escolares, é possível afirmar que o aumento da escolaridade implica taxa menor de epêntese.

TABELA 3 - TAXA DE EPÊNTESE NA AMOSTRA DE CURITIBA (QUATRO FAIXAS ESCOLARES)

\begin{tabular}{l|ll|l}
\hline & Aplicação/Total & $\%$ & Peso relativo \\
\hline Primário & $8 / 23$ & 35 & 0,58 \\
Ginásio & $37 / 69$ & 54 & 0,58 \\
Colegial & $48 / 94$ & 51 & 0,60 \\
Superior & $42 / 121$ & 35 & 0,36 \\
Total & $135 / 307$ & 44 & \\
\hline
\end{tabular}

Input: 0,41

Significância: 0,010

Na tabela 3 observamos que as taxas de realização de epêntese nas faixas escolares primário, ginásio e colegial ficaram bastante próximas entre si $(0,58$ as 
duas primeiras, 0,60 a terceira). O colegial surpreende porque se esperava, a partir dos resultados de Porto Alegre, um peso relativo mais próximo do ponto neutro. Por outro lado, o nível superior apresenta-se conforme o esperado, com taxa de realização significativamente mais baixa $(0,33)$. Podemos, portanto, dizer que a escolaridade desempenha papel na realização de epêntese para os informantes de Curitiba, apesar do comportamento díspar do fator colegial.

Ao analisarmos as duas amostras, Porto Alegre e Curitiba, em conjunto, constatamos que o incremento da escolaridade realmente se correlaciona inversamente com a taxa de realização de epêntese, conforme pode se ver na tabela abaixo.

\begin{tabular}{|c|c|c|c|}
\hline & Aplicação/Total & $\%$ & Peso relativo \\
\hline Primário & $37 / 62$ & 60 & 0,69 \\
\hline Ginásio & $62 / 103$ & 60 & 0,67 \\
\hline Colegial & $95 / 202$ & 47 & 0,56 \\
\hline Superior & $98 / 294$ & 33 & 0,36 \\
\hline Total & $292 / 661$ & 44 & \\
\hline
\end{tabular}

Input: 0,44

Significância: 0,000

Para termos certeza de que o papel da escolaridade não seja apenas uma idiossincrasia dos informantes de Porto Alegre, mas de que ela desempenhe globalmente papel importante na realização de epêntese, complementamos a análise com a amostra de escolaridade superior de Florianópolis.

TABELA 5 - AMOSTRA FLORIANÓPOLIS (QUATRO FAIXAS ESCOLARES)

\begin{tabular}{l|l|l|l}
\hline & Aplicação/Total & $\%$ & Peso relativo \\
\hline Primário & $18 / 38$ & 47 & 0,55 \\
Ginásio & $4 / 25$ & 16 & 0,21 \\
Colegial & $42 / 86$ & 49 & 0,56 \\
Superior & $34 / 78$ & 44 & 0,51 \\
Total & $98 / 227$ & 43 & \\
\hline
\end{tabular}

Input: 0,43

Significância: 0,020

Embora a diferença entre as faixas de escolaridade não seja muito nítida, e a faixa do ginásio apresente um comportamento aparentemente díspar, ainda assim, o resultado não contraria os resultados para as amostras anteriores.

Os dados apresentados evidenciam que a variação está correlacionada à escolaridade; quanto mais escolarizado o indivíduo, menor será sua taxa de 
COLLISCHONN, G. Epêntese vocálica no português do Sul...

realização de epêntese. Entretanto, não nos parece que seja o caso de o falante mais escolarizado apresentar uma taxa mais baixa de epêntese porque procura conscientemente evitar formas estereotipadas. Entendemos que essa idéia não tem suporte nos nossos resultados. As outras variáveis sociais não apontam nessa direção.

Não se constatam diferenças entre homens e mulheres, nem entre mais velhos e mais novos, por exemplo, o que exemplificamos com as tabelas abaixo.

TABELA 6 - AMOSTRA PORTO ALEGRE (QUATRO FAIXAS DE ESCOLARIDADE) - VARIÁVEL SEXO

\begin{tabular}{l|l|l|l}
\hline & Aplicação/Total & $\%$ & Peso relativo \\
\hline Masculino & $96 / 214$ & 45 & 0,50 \\
Feminino & $62 / 141$ & 44 & 0,67 \\
Total & $158 / 355$ & 45 & \\
\hline
\end{tabular}

Input: 0,45

TABELA 7 - AMOSTRA PORTO ALEGRE (QUATRO FAIXAS DE ESCOLARIDADE) - VARIÁVEL IDADE

\begin{tabular}{l|l|l|l}
\hline & Aplicação/Total & $\%$ & Peso \\
\hline Menos de 50 & $44 / 122$ & 36 & 0,41 \\
Mais de 50 & $114 / 233$ & 49 & 0,55 \\
Total & $158 / 355$ & 45 & \\
\hline
\end{tabular}

Input: 0,45

Embora se constate nessas amostras uma tendência de os informantes mais idosos apresentarem uma porcentagem de realização de epêntese superior à dos informantes menos idosos, a variável, não obstante, não foi selecionada como estatisticamente significativa, o que indicaria para uma variação estável nessas comunidades.

Além disso, há pouca manifestação a respeito do fenômeno por parte dos falantes. Existem estereótipos com epêntese, mas são alguns vocábulos: peneu, adevogado, pisicólogo. Muitos falantes mencionam essas palavras, quando solicitados a dizer quem fala errado, mas esquecem outras formas extremamente freqüentes: digno, aspecto, observa, e assim por diante.

Portanto, para as amostras das capitais, constata-se que não há evidências de papel para outras variáveis extralingüísticas (além das diferenças diatópicas observadas na tabela 1). Entretanto, embora a variação não seja acessível ao falante, a escolaridade parece ter um papel como inibidora. Acreditamos que a consciência da forma escrita deve ter alguma influência sobre a variação. 
Entendemos que esse é um caso em que não é a prescritividade escolar que está agindo, mas sim, o fato de que a forma escrita tem um impacto direto sobre a competência oral do falante que usa a escrita.

\section{As amostras de Panambi e Blumenau}

Caso diferente é o de Panambi/Blumenau; em Keller (1999) constatou-se que há indícios de uma mudança em curso, em direção a maior taxa de realização de epêntese.

TABELA 8 - AMOSTRA PANAMBI/BLUMENAU - VARIÁVEL IDADE

\begin{tabular}{l|l|c|c}
\hline & Aplicação/Total & $\%$ & Peso \\
\hline Menos de 50 & $62 / 173$ & 36 & 0,68 \\
Mais de 50 & $25 / 194$ & 13 & 0,34 \\
\hline
\end{tabular}

Input: 0,19

Significância: 0,000

Poderíamos interpretar também esse caso como de um fenômeno cuja variação é inconsciente, ou seja, o falante não sabe da variação (apenas o fato de não ter mais contato tão forte com a língua alemã estaria determinando a mudança). Entretanto, acreditamos que, na verdade, há aí variação conscientemente controlada pelo falante: ele está mudando o seu modo de falar para se ajustar à fala prestigiada de centros maiores. É um caso do que se chama de mudança from above, que sempre envolve consciência do falante.

Outra evidência a favor dessa posição é o fato observado de as formas que são nativas da língua alemã serem predominantemente realizadas sem epêntese. Isso foi observado através de uma variável lingüística que considerava se a palavra-alvo era uma palavra nativa ou um empréstimo. O resultado demonstra que o falante bilíngüe tem consciência da variação em estudo e usa conscientemente as variantes dependendo da origem da palavra empregada. A mesma variável não teve papel nas outras amostras, ou, em alguns casos, o fator empréstimo pareceu favorecer a epêntese (caso de Porto Alegre, quando consideradas apenas as três primeiras faixas de escolaridade).

Há ainda que lembrar que, diferentemente das outras amostras, a escolaridade não teve um papel inibidor da epêntese; a variável não foi selecionada. 
COLLISCHONN, G. Epêntese vocálica no português do Sul...

TABELA 9 - AMOSTRA PANAMBI/BLUMENAU - VARIÁVEL ESCOLARIDADE

\begin{tabular}{l|l|l|l}
\hline & Aplicação/Total & $\%$ & Peso relativo \\
\hline Primário & $23 / 101$ & 23 & 0,49 \\
Ginásio & $25 / 105$ & 24 & 0,50 \\
Colegial & $39 / 162$ & 24 & 0,51 \\
Total & $87 / 368$ & 24 & \\
\hline
\end{tabular}

Input: 0,24

Esses resultados demonstram que o fenômeno tem uma interpretação sociolingüística diferente nas comunidades de Panambi/Blumenau do que no conjunto das capitais.

\section{A amostra de Flores da Cunha}

Também diferente é a situação em Flores da Cunha. Aqui, são selecionadas duas variáveis extralingüísticas, sexo e idade (nessa ordem):

TABELA 9 - AMOSTRA FLORES DA CUNHA - VARIÁVEL SEXO

\begin{tabular}{l|l|l|l}
\hline & Aplicação/Total & $\%$ & Peso relativo \\
\hline Masculino & $29 / 82$ & 35 & 0,37 \\
Feminino & $49 / 88$ & 56 & 0,62 \\
Total & $78 / 170$ & 44 & \\
\hline
\end{tabular}

Input: 0,44

Significância: 0,032

TABELA 10 - AMOSTRA FLORES DA CUNHA - VARIÁVEL IDADE

\begin{tabular}{l|l|l|l}
\hline & Aplicação/Total & $\%$ & Peso relativo \\
\hline Mais de 50 & $33 / 94$ & 35 & 0,40 \\
Menos de 50 & $45 / 76$ & 59 & 0,62 \\
Total & $78 / 170$ & 44 & \\
\hline
\end{tabular}

Input: 0,44

Significância: 0,032

Esses resultados caracterizam uma situação de mudança em curso, liderada pelas mulheres. A variável escolaridade, não foi selecionada. A tabela abaixo mostra por quê. 
TABELA 11 - AMOSTRA FLORES DA CUNHA - VARIÁVEL ESCOLARIDADE

\begin{tabular}{l|l|l|l}
\hline & Aplicação/Total & $\%$ & Peso relativo \\
\hline Primário & $15 / 33$ & 45 & 0,50 \\
Ginásio & $19 / 37$ & 51 & 0,55 \\
Colegial & $44 / 100$ & 44 & 0,48 \\
Total & $78 / 170$ & 44 & \\
\hline
\end{tabular}

Input: 0,46

Como se pode ver, não há diferença nas taxas de aplicação de epêntese entre as distintas faixas de escolaridade, apesar de, mais uma vez comprovarmos que o número de formas-alvo aumenta incrivelmente com o aumento da escolaridade.

Ainda, para fins de comparação, em Blumenau e Panambi não há diferenças estatisticamente significativas quanto ao sexo dos informantes (a variável não foi selecionada).

TABELA 12 - AMOSTRA BLUMENAU - VARIÁVEL SEXO

\begin{tabular}{l|l|l|l}
\hline & Aplicação/Total & $\%$ & Peso relativo \\
\hline Masculino & $20 / 90$ & 22 & 0,49 \\
Feminino & $23 / 96$ & 24 & 0,51 \\
Total & $43 / 186$ & 23 & \\
\hline
\end{tabular}

Input: 0,24

TABELA 13 - AMOSTRA PANAMBI - VARIÁVEL SEXO

\begin{tabular}{l|l|l|l}
\hline & Aplicação/Total & $\%$ & Peso relativo \\
\hline Masculino & $24 / 120$ & 20 & 0,44 \\
Feminino & $20 / 61$ & 33 & 0,61 \\
Total & $44 / 181$ & 24 & \\
\hline
\end{tabular}

Input: 0,24

\section{Discussão}

Cabe discutir um pouco a diferença entre variação e mudança lingüística. Pode-se afirmar que muitas mudanças têm na sua origem processos sincrônicos de fala casual. Como afirmam Milroy e Milroy (1985), é preciso distinguir uma inovação de uma mudança lingüística: a primeira certamente inclui variação fonética (low-level), ao passo que a segunda somente inicia quando uma variante 
COLLISCHONN, G. Epêntese vocálica no português do Sul...

adquire um papel/significado social na comunidade de fala. Variação fonética, portanto, é uma condição necessária mas não suficiente para a mudança. Mudança, especialmente se for from above, sempre irá envolver consciência do falante.

É o que temos aqui com relação a essas três comunidades bilíngües, em oposição às comunidades não predominantemente bilíngües de Porto Alegre, Curitiba e Florianópolis. Nas comunidades bilíngües, há, no nosso entender, uma consciência maior das formas com epêntese. O falante percebe essa realização como categórica, ao passo que o falante de comunidades como Porto Alegre e Curitiba a percebe com gradiente.

Essa diferença remete à distinção que Kiparsky (1988) projeta para regras fonológicas do tipo lexical e pós-lexical. Para ele, mudanças difusionistas se comportam como regras fonológicas lexicais e mudanças "neogramáticas" como regras pós-lexicais. Cada tipo de regra é identificada com uma síndrome de características. Por exemplo, regras lexicais aplicam-se somente no interior de palavras, podem ter exceções lexicais, podem ser sensíveis a informação morfológica, precedem todas as regras pós-lexicais, ao passo que as regras póslexicais podem aplicar-se também através de fronteiras de palavra, não podem ter exceções lexicais, não podem referir-se a informação morfológica, nunca precedem regras lexicais etc.

Essa proposta tem o mérito de fazer previsões a respeito do comportamento sociolingüístico das regras fonológicas variáveis, conectando determinadas questões da fonologia teórica com aquelas que emergem do paradigma quantitativo da sociolingüística.

Dentre as características que distinguem um tipo de regra da outra (cf. Kiparsky 1988; McMahon, 1994), interessam-nos em um primeiro momento as seguintes:

\begin{tabular}{l|l}
\hline Regras lexicais & Regras pós-lexicais \\
\hline Output binário/discreto & Pode ter output gradiente/escalar \\
\hline $\begin{array}{l}\text { Observável/categorizável (i.e. acessível } \\
\text { à intuição do falante nativo) }\end{array}$ & Falantes não têm consciência \\
\hline Sensível a informação morfológica/lexical & $\begin{array}{l}\text { Condicionamento puramente fonético } \\
\text { (i.e. não pode referir-se a informação } \\
\text { morfológica/lexical) }\end{array}$ \\
\hline
\end{tabular}

Ora, as características acima indicadas na coluna da esquerda parecem atribuíveis à variação da epêntese em Panambi, Blumenau e Flores da Cunha, ao passo que as da coluna da direita parecem refletir melhor a realidade da regra em Porto Alegre e Curitiba (e, possivelmente, em Florianópolis). 
Como vimos, a regra parece ser acessível ao falante em Panambi, Blumenau e Flores da Cunha, funcionando como um marcador social, ao passo que não parece ser acessível aos falantes de Porto Alegre e Curitiba (e, possivelmente, em Florianópolis). Além disso, em Panambi e Blumenau, verificou-se que o falante aplicava mais a regra em palavras que identifica como sendo do português e menos em palavras que, embora apresentassem contexto de aplicação da epêntese, eram nativas do alemão ou em nomes próprios de origem alemã.

Além das questões mais tradicionais, outras são agora colocadas a respeito do fenômeno variável em análise, como estas, entre outras: (i) com que outras regras o fenômeno interage?; (ii) quais são as palavras (formas-alvo) que manifestam o fenômeno de maneira categórica?; (iii) quais são as palavras que nunca manifestam aplicação?; (iv) o fenômeno pode ser transferido para L2 ou não?

Estas questões ficam para serem aprofundadas em investigações futuras, o que significa que outras bases de dados devem também ser consideradas.

As observações acima, a respeito das diferenças entre as comunidades de Porto Alegre, Curitiba e Florianópolis, por um lado, e Panambi, Blumenau e Flores da Cunha, por outro, parecem indicar que a epêntese tem um status diferenciado: em Porto Alegre e Curitiba, ela teria um caráter pós-lexical (é um fenômeno condicionado foneticamente, que tem um status gradiente, que sofre interferência da velocidade da fala e que não interage com regras lexicais); em Panambi, Blumenau e Flores da Cunha, aparentemente, o status é de regra lexical ou de transição entre os dois componentes, lexical e pós-lexical.

\section{RESUMO}

Pesquisa variacionista sobre a incidência de vogal epentética - para desfazer encontros consonantais em palavras como admitir, tecnologia, opção, entre outras - no português do sul do Brasil, com dados do Banco Varsul, mostra que o fenômeno tem uma distribuição bastante característica no tecido geográfico/social. Nesta comunicação, discutimos os resultados obtidos para as diferentes amostras do Varsul analisadas, levando em consideração variáveis tais como escolaridade, idade e sexo.

Palavras-chave: variação, fonologia, epêntese. 


\begin{abstract}
Research about the variable incidence of an epenthetic vowel to break untenable consonantal sequences in words like admitir, tecnologia, opção, in Brazilian Portugese, with data from the corpus of Projeto Varsul, has shown that the fenomenon has a characteristic distribution in the social and geographic tissue. In this work, we discuss the results obtained for the different samples, considering variables like educational level and age and sex.

Key-words: variation, phonology, epenthesis.
\end{abstract}

\title{
REFERÊNCIAS
}

BISOL, L.; BRESCANCINI, C. (Orgs.). Fonologia e variação: recortes do português brasileiro (VARSUL). Porto Alegre: EDIPUCRS, 2002.

COLLISCHONN, G. A epêntese vocálica no português do sul do Brasil: análise variacionista e tratamento pela Teoria da Otimalidade. Letras de Hoje, v. 35, n. 1, p. $285-$ $318,2000$.

. A epêntese vocálica no português do sul do Brasil. In: BISOL, L.; BRESCANCINI, C. (Orgs.). Fonologia e variação: recortes do português brasileiro (VARSUL). Porto Alegre: EDIPUCRS, 2002.

ITÔ, J. Syllabe Theory in Prosodic Phonology. Massachussetts, 1986. Tese (Doutorado)

- University of Massachussets.

KELLER, T. O fenômeno da epêntese no português falado em Panambi e Blumenau. Cadernos do I.L., Porto Alegre, 1999.

KIPARSKY, P. Phonological change. In: NEWMEYER, F. (Ed.). Linguistics: the Cambridge survey. Cambridge: CUP, 1988. v. 1: Linguistic Theory: foundations. p. 363-415.

. The phonological basis of sound change. In: GOLDSMITH, J. (Ed.). The Handbook of phonological theory. Cambridge, Mass.: Blackwell, 1995. p. 640-670.

LABOV, W. Resolving the Neogrammarian controversy. Language, v. 57, p. 267-308, 1981.

. Principles of linguistic change: internal factors. Oxford: Blackwell, 1994. 
McMAHON, A. Understanding Language Change. Cambridge: CUP, 1994.

MILROY, J.; MILROY, L. Linguistic change, social network and speaker innovation. Journal of Linguistics, n. 21, p. 339-384, 1985.

MOLLICA, M. C.; RONCARATI, C. Questões teórico-descritivas em Sociolingüística e em Sociolingüística Aplicada e uma proposta de agenda de trabalho. DELTA, São Paulo, v. 17, special issue, 2001.

PIGOTT, G. Epenthesis and syllabe weight. Natural Language and Linguistic Theory, v. 3, p. 283-326, 1995. 